\title{
Nonsyndromic cleft lip and/or palate: A multicenter study of the dental anomalies involved
}

\author{
Carlos Menezes ${ }^{1}$, José-Alcides de Arruda ${ }^{2}$, Leni-Verônica Silva ${ }^{2}$, João-Luiz Monteiro ${ }^{3}$, Pérola Caribé ${ }^{4}$, Pa- \\ mella Álvares ${ }^{4}$, Maria-Cristina Almeida ${ }^{5}$, José-Carlos Coelli ${ }^{6}$, Fernanda Goldemberg ${ }^{5}$, Marcia Silveira ${ }^{4}$, \\ Ana-Paula Sobral ${ }^{4}$, Daniela-Franco Bueno ${ }^{1,5}$
}

\author{
${ }^{1}$ Institute of Teaching and Research of Hospital Sírio Libanês, São Paulo, SP, Brazil \\ ${ }^{2}$ Department of Oral Surgery and Pathology, School of Dentistry, Universidade Federal de Minas Gerais, Belo Horizonte, MG, \\ Brazil \\ ${ }^{3}$ Department of Oral and Maxillofacial Surgery, School of Dentistry, Universidade de Pernambuco, Camaragibe, PE, Brazil \\ ${ }^{4}$ Department of Oral and Maxillofacial Pathology, School of Dentistry, Universidade de Pernambuco, Camaragibe, PE, Brazil \\ ${ }^{5}$ Department of Orthodontics, Hospital Municipal Infantil Menino Jesus, São Paulo, SP, Brazil \\ ${ }^{6}$ Department of Orthodontics, Centrinho Prefeito Luiz Gomes, Joinville, SC, Brazil
}

\section{Correspondence:}

Hospital Sirio Libanês

Rua Adma Jafet 115, Bloco B-1

Banco de Sangue de Cordão Umbilical

Bela Vista, São Paulo - SP, Brazil

Zip code: $01308-060$

dbuenousp@gmail.com

\begin{abstract}
Menezes C, de Arruda JA, Silva LV, Monteiro JL, Caribé P, Álvares P, Almeida MC, Coelli JC, Goldemberg F, Silveira M, Sobral AP, Bueno DF. Nonsyndromic cleft lip and/or palate: A multicenter study of the dental anomalies involved. J Clin Exp Dent. 2018;10(8):e746-50.

http://www.medicinaoral.com/odo/volumenes/v10i8/jcedv10i8p746.pdf
\end{abstract}

Received: 15/04/2018

Accepted: 08/06/2018

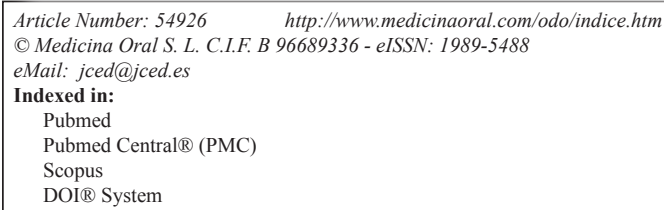

\begin{abstract}
Background: Nonsyndromic cleft lip and/or palate (NSCL/P) is the most common craniofacial malformation. Due to the anatomical defect present in the alveolar process, these patients tend to exhibit more dental anomalies. The aim of this study was to identify the prevalence of dental anomalies in patients with NSCL/P by obtaining orthodontic documentation from Brazilian Centers for cleft lip and palate treatment.

Material and Methods: A retrospective analysis (2000-2014) was conducted on orthodontic archives, radiographs and medical records of NSCL/P of 524 patients under orthodontic treatment. Panoramic radiographs and intra-oral photographs were examined to identify these anomalies. Categorical variables were expressed in terms of frequencies and percentages and analyzed using the Chi-Square test. The level of significance was set at $p \leq 0.05$ in all analyses.

Results: Approximately $83.3 \%$ of the individuals had at least one dental anomaly. Tooth agenesis was the most common abnormality found in those patients $(87.8 \%)(\mathrm{p}<0.001)$. Also, the largest number of dental anomalies was detected in the group of unilateral left clefts. The prevalence of dental anomalies in the present sample of NSCL/P patients was high and reached the highest levels in patients with alveolar bone clefts.

Conclusions: This study describes the most common dental anomalies observed in patients with NSCL/P. These abnormalities can cause significant problems that may be solved or minimized by early diagnosis and treatment.
\end{abstract}

Key words: Cleft lip and/or palate, dental care for children, epidemiology, craniofacial abnormalities. 


\section{Introduction}

Cleft lip (CL), cleft palate (CP) and cleft lip and palate (CLP) are the most common craniofacial malformations detected at birth, representing $25 \%$ of all congenital craniofacial defects. Approximately 1 in 700 live births has a kind of cleft. A multifactorial model of genetic inheritance has been suggested for nonsyndromic cleft lip and/ or palate (NSCL/P) based on the interaction of genetic and environmental factors $(1,2)$. It is very common to observe different kinds of tooth anomalies in children with cleft lip and/or palate (CL/P), such as supernumerary teeth or missing teeth, microdontia, rotated teeth, hypoplasia, transpositions, and root deviation, usually detected on the cleft side (3-5). Tooth anomalies can be a challenge to the multidisciplinary health team treating these patients, but early detection improves treatment outcomes and orthodontic and surgical planning can be properly executed to obtain adequate aesthetic and functional results (3-9).

The development of $\mathrm{CL} / \mathrm{P}$ and tooth germs involves a very close embryologic relationship in terms of timing and anatomical position $(3,6,10,11)$. Johnson et al. (12) have suggested that gene alterations associated with oral clefts can also produce many disturbances in other tissues, including changes in the dental lamina signaling pathway during odontogenesis, leading to dental malformations.

Data about the prevalence of dental anomalies in Brazilians NSCL/P are scarce. Therefore, to expand our knowledge about this topic, we evaluated the samples of three referral centers located in representative regions of Brazil (Northeast, Southeast and South).

\section{Material and Methods}

-Study design and ethical approval

Data regarding 524 patients with NSCL/P were analyzed in a retrospective analysis (2000-2014). Data were obtained from three referral centers in Brazil: Instituto Materno Infantil de Pernambuco, in Pernambuco (Northeast region), Hospital Municipal Infantil Menino Jesus, in São Paulo (Southeast region), and Centrinho Prefeito Luis Gomes, in Santa Catarina (South region). The hospitals involved in this study are reference centers for the treatment and rehabilitation of individuals with any kind of malformation, including oral clefts. However, only NSCL/P patients were included in the present investigation. The study was approved by the Ethics Committee of the Sírio Libanês Hospital (Approval No. 0020.097.000-09) and was conducted in accordance with the guidelines of the Declaration of Helsinki.

\section{-Sample}

Data regarding gender, age, type of cleft and dental anomalies were collected from a total of 524 patients with NSCL/P aged $\leq 18$ years. The patients were divided into groups according to the Spina (13) classification of clefts: unilateral right CL/P (URCLP), unilateral left CL/P (ULCLP), bilateral CL/P (BCLP), and cleft palate only (CP). Form and number of anomalies were considered, excluding the third molar. One method for the assessment of the presence of dental anomalies was the use of panoramic and periapical radiographs, with the evaluators being blind to possible records of these anomalies in the medical records. Furthermore, intra-oral photographs were retrieved. All patients were evaluated by a geneticist in order to determine and exclude any case presenting an association between $\mathrm{CL} / \mathrm{P}$ and some syndrome.

The radiographs were analyzed by four independent specialists (an oral and maxillofacial pathologist, an oral and maxillofacial radiologist and two orthodontists) with more than 20 years of experience. Radiographs with acceptable sharpness, contrast and density were considered in the analysis. Records with previous tooth extractions and incomplete $\mathrm{CL} / \mathrm{P}$ description, as well as radiographs with poor image quality were excluded.

-Data analysis

Categorical variables are reported as frequencies and percentages and were analyzed by the Chi-square test and the Fisher exact test, with the level of significance set at $5 \%(p \leq 0.05)$ in all analyses. Statistical modeling and the tests were performed using Statistical Package for the Social Sciences software, version 21.0 (SPSS, Inc., Chicago, IL, USA).

\section{Results}

Of the 524 patients studied, 283 were males (54\%) and 241 were females (46\%). Regarding the number of patients who were undergoing orthodontic treatment at each reference center, 231 (44\% of the total sample) were treated at Instituto Materno Infantil de Pernambuco (Northeast region), 156 (29.7\% of the total sample) at Hospital Municipal Infantil Menino Jesus (Southeast region), and 137 (26.1\% of the total sample) at Centrinho Prefeito Luis Gomes (Southern region).

According to the Spina (13) classification, 105 patients had URCLP (20\%), 224 had ULCLP (42.7\%) (Fig. 1), 110 had BCLP (20.9\%), and 85 had only CP (16.2\%) $(p<0.001)$ (Table 1).

At least one dental anomaly was observed in 437 patients, corresponding to $83.3 \%$ of the total sample $(p<0.001)$ (Table 2). The most frequent dental anomaly was tooth agenesis (Fig. 2), which occurred in 271 out of 437 patients, representing $62 \%$ of all dental anomalies in this study. Agenesis of the upper lateral incisors on the alveolar cleft side was the anomaly most frequently observed ( $87 \%$ of all cases of tooth agenesis) (Table 2). Rotated tooth was the second tooth abnormality most frequently detected in this sample $(n=142,32.4 \%)$, with the central incisor being the tooth most frequently involved. A total of 104 patients had supernumerary teeth 


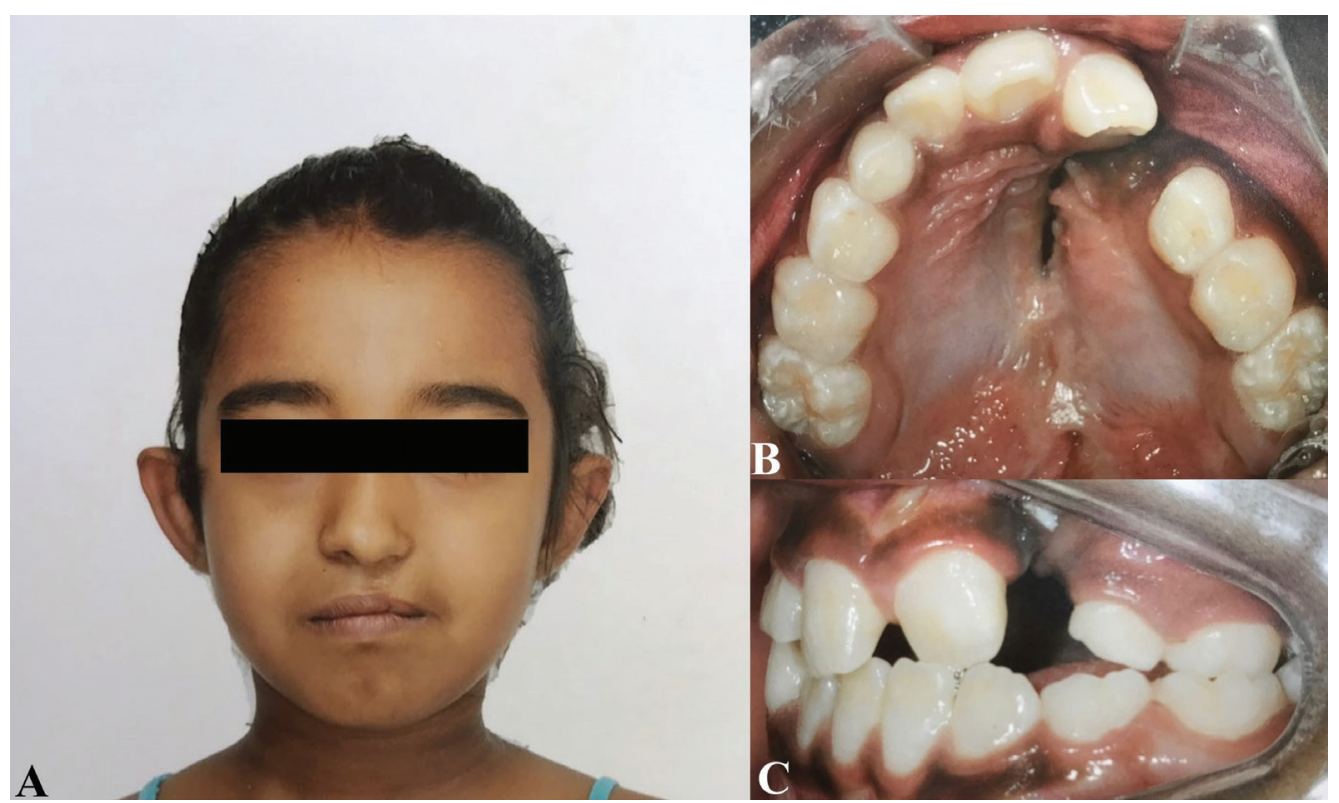

Fig. 1: A. A 9-year old patient showing repaired unilateral left cleft lip and palate. B. Occlusal view of cleft lip and palate. C. Lateral view of cleft lip and palate showing the lateral agenesis.

Table 1: Distribution of patient according to type of cleft and gender.

\begin{tabular}{|l|c|c|c|c|c|}
\hline & \multicolumn{5}{|c|}{ Cleft type } \\
\hline Gender & URCLP, n (\%) & ULCLP, n (\%) & BCLP, n (\%) & CP, n (\%) & Total (\%) \\
\hline Male & $50(9.5)$ & $120(22.8)$ & $51(9.6)$ & $62(11.8)$ & $283(100)$ \\
\hline Female & $55(10.5)$ & $104(19.8)$ & $59(11.2)$ & $23(4.3)$ & $241(100)$ \\
\hline Total & $105(20)$ & $224(42.7)$ & $110(20.9)$ & $85(16.2)$ & $524(100)$ \\
\hline
\end{tabular}

$p$-value $<0.001$ (Chi Square test).

Table 2: Distribution of patient according to type of cleft and presence or not of dental anomalies.

\begin{tabular}{|l|c|c|c|c|c|c|c|c|}
\hline Anomalies & \multicolumn{4}{|c|}{ Unilateral cleft } & \multicolumn{2}{c|}{ Bilateral cleft } & \multicolumn{2}{c|}{ Cleft palate } \\
\hline & \multicolumn{2}{|c|}{ Right } & \multicolumn{2}{c|}{ Left } & \multicolumn{3}{c|}{} \\
\hline & $\mathrm{n}$ & $\%$ & $\mathrm{n}$ & $\%$ & $\mathrm{n}$ & $\%$ & $\mathrm{n}$ & $\%$ \\
\hline Presence & 111 & 21.1 & 195 & 37.2 & 95 & 18.1 & 36 & 6.8 \\
\hline Absence & 11 & 2 & 14 & 2.6 & 9 & 1.7 & 53 & 10.1 \\
\hline
\end{tabular}

$p$-value $<0,001$ (Chi Square test).

$(23.7 \%)$ and 78 patients had impacted teeth $(17.8 \%)$, with the canine being the most affected tooth. The other dental anomalies observed were: microdontia $(13 \%)$, ectopic tooth $(6.4 \%)$, hypoplasia $(3.2 \%)$, dilacerations $(0.9 \%)$, and hypercementosis $(0.6 \%)$ (Table 3$)$.

\section{Discussion}

Considering the high incidence of clefts around the world, it is extremely important for the multidisciplinary health team to be familiarized with dental anomalies in order to carry out the correct orthodontic and surgical 


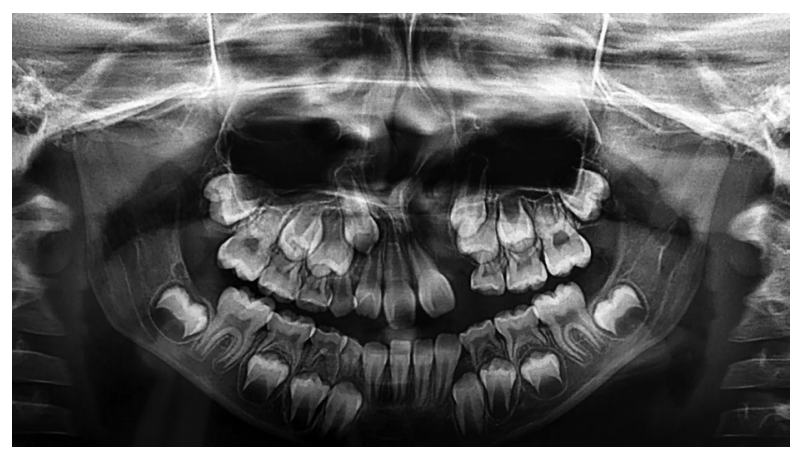

Fig. 2: Panoramic radiograph showing agenesis of the left lateral incisor.

Table 3: Frequency of dental anomalies in 437 patients with NSCL/P.

\begin{tabular}{|l|c|}
\hline Dental anomaly & $\begin{array}{c}\text { Number of affected individuals } \\
\text { with anomalies (\%) }\end{array}$ \\
\hline Tooth agenesis & $271(62.0)$ \\
\hline Rotated tooth & $142(32.4)$ \\
\hline $\begin{array}{l}\text { Supernumeraries } \\
\text { teeth }\end{array}$ & $104(23.7)$ \\
\hline Impacted teeth & $78(17.8)$ \\
\hline Microdontia & $57(13.0)$ \\
\hline Ectopic tooth & $28(6.4)$ \\
\hline Hypoplasia & $14(3.2)$ \\
\hline Dilacerations & $4(0.9)$ \\
\hline Hypercementosis & $3(0.6)$ \\
\hline
\end{tabular}

treatment for these children and adolescents. The aim of the present study was to determine the prevalence of dental anomalies in NSCL/P patients at reference centers in distinct regions of Brazil.

To the best of our knowledge, this is the first multicenter study conducted in Brazil which describes the prevalence of dental anomalies in NSCL/P patients using data obtained from patients who were undergoing orthodontic treatment at specialized centers located in three Brazilian regions (Northeast, Southeast and South). In this study we observed that at least $83.3 \%$ of our NSCL/P sample had some type of tooth alteration. A recent study which investigated a large cohort of children with NSCLP, their relatives, and controls found a significantly higher risk for dental anomalies compared to the general population. However, the findings suggested that the affected families did not have a higher genetic risk for dental anomalies than the general population and that the higher prevalence of these anomalies was mainly a consequence of various surgical interventions (14). However, this higher prevalence $(3,11,15,16)$ of dental anomalies observed in cleft patients has been reported to be related to the existence of a common genetic link between oral clefts and dental anomalies in other studies (17). For instance, genes whose mutations are associated with tooth agenesis, such as MSX1 and PAX9, also contain single nucleotide polymorphisms as genetic risk factors for orofacial clefts (18). Other studies have shown that the severity of dental anomalies varies according to the complexity of the clefts $(4,19)$.

The most common tooth alteration observed in our sample was tooth agenesis (62\% of all dental anomalies). Tooth agenesis occurs approximately three times more frequently on the cleft than on the non-cleft side (20). The upper lateral incisor was the most common tooth missing on the alveolar cleft side, representing $87 \%$ of all cases of dental agenesis detected in our study. Other recent studies on NSCL/P conducted in Italy (21), and in Greece (22) also agree with these findings. It is important to identify this lateral incisor agenesis before performing an alveolar bone graft in $\mathrm{CL} / \mathrm{P}$ patients since this anomaly affects surgical and orthodontic planning. For instance, the space may be maintained for future placement of a dental implant, or the canine may be moved closer.

Other abnormalities are microdontia, hypoplasia, impaction, rotation, peg teeth, and root deviation $(23,24)$. Anodontia can occur by absent or incomplete development of the tooth germ, $(23,24)$. Three hypotheses have been raised for supernumerary teeth: the first states that development starts with remnants of epithelial cells from the disintegration of the dental lamina; the second suggests that development occurs from the complete division of a dental germ, and the third and most accepted one states that hyperactivity of the dental lamina occurs, causing invagination from the oral epithelial lining (25). In addition, peg teeth are frequently found in $\mathrm{CL} / \mathrm{P}$ patients. It is most common in cases where the lateral incisor is not absent but has a deformed shape (25). Hypoplasia is another dental anomaly found at higher frequency in patients with $\mathrm{CL} / \mathrm{P}$, affecting more commonly the central incisors $(4,24,25)$.

The impaction of canines in the permanent dentition is very common in these individuals. This change in position has an important impact on the development of dentition and occlusion (26), so that early detection is essential. According to Vellone et al. (27), agenesis does not play any role in the process of canine eruption, while supernumeraries do.

One limitation of this study is that only patients under orthodontic treatment were evaluated. Therefore, some data should be interpreted with caution. For example, regarding the prevalence of rotational teeth, it may be possible that some patients had this condition already corrected at some point during orthodontic treatment. 


\section{Conclusions}

In summary, this study provides information about the dental anomalies observed in patients with NSCL/P, knowledge that is very important for craniofacial surgery planning. With an early diagnosis of these dental alterations and their orthodontic treatment, these abnormalities may be solved or minimized in cleft lip and palate patients and an aesthetic and functional pattern of dental arches can be obtained.

\section{References}

1. Dixon MJ, Marazita ML, Beaty TH, Murray JC. Cleft lip and palate: understanding genetic and environmental influences. Nat Rev Genet. 2011;12:167-78.

2. Murray JC. Face facts: genes, environment, and clefts. Am J Hum Genet. 1995;57:227-32.

3. Sá J, Mariano LC, Canguçu D, Coutinho TS, Hoshi R, Medrado AP, et al. Dental anomalies in a Brazilian cleft population. Cleft Palate Craniofac J. 2016;53:714-9.

4. Eerens K, Vlietinck R, Heidbüchel K, Van Olmen A, Derom C, Willems $\mathrm{G}$, et al. Hypodontia and tooth formation in groups of children with cleft, siblings without cleft, and nonrelated controls. Cleft Palate Craniofac J. 2001;38:374-8.

5. Vieira AR. Oral clefts and syndromic forms of tooth agenesis as models for genetics of isolated tooth agenesis. J Dent Res. 2003;82:162-5. 6. Letra A, Menezes R, Granjeiro JM, Vieira AR. Defining subphenotypes for oral clefts based on dental development. J Dent Res. 2007;86:986-91.

7. Rawashdeh MA, Abu Sirdaneh EO. Crown morphologic abnormalities in the permanent dentition of patients with cleft lip and palate. J Craniofac Surg. 2009;20:465-70

8. Walker SC, Mattick CR, Hobson RS, Steen IN. Abnormal tooth size and morphology in subjects with cleft lip and/or palate in the north of England. Eur J Orthod. 2009;31:68-75.

9. Wu TT, Chen PK, Lo LJ, Cheng MC, Ko EW. The characteristics and distribution of dental anomalies in patients with cleft. Chang Gung Med J. 2011;34:306-14.

10. Menezes R, Vieira AR. Dental anomalies as part of the cleft spectrum. Cleft Palate Craniofac J. 2008;45:414-9.

11. Paranaiba LM, Coletta RD, Swerts MS, Quintino RP, de Barros LM, Martelli-Júnior H. prevalence of dental anomalies in patients with nonsyndromic cleft lip and/or palate in a Brazilian population. Cleft Palate Craniofac J. 2013;53:400-5.

12. Johnson RL, Rothman AL, Xie J, Goodrich LV, Bare JW, Bonifas $\mathrm{JM}$, et al. Human homolog of patched, a candidate gene for the basal cell nevus syndrome. Science. 1996;272:1668-71.

13. Spina V. A proposed modification for the classification of cleft lip and cleft palate. Cleft Palate J. 1973;10:251-2.

14. Howe BJ, Cooper ME, Vieira AR, Weinberg SM, Resick JM, Nidey NL, et al. Spectrum of dental phenotypes in nonsyndromic orofacial clefting. J Dent Res. 2015;94:905-12.

15. Abreu MH, Lee KH, Luquetti DV, Starr JR. Temporal trend in the reported birth prevalence of cleft lip and/or cleft palate in Brazil, 2000 to 2013. Birth Defects Res A Clin Mol Teratol. 2016;106:789-92.

16. Martelli-Junior H, Porto LV, Martelli DR, Bonan PR, Freitas AB, Della Coletta R. Prevalence of nonsyndromic oral clefts in a reference hospital in the state of Minas Gerais, Brazil, between 2000-2005. Braz Oral Res. 2007;21:314-7.

17. Tannure PN, Oliveira CA, Maia LC, Vieira AR, Granjeiro JM, Costa $\mathrm{M}$ de $\mathrm{C}$. Prevalence of dental anomalies in nonsyndromic individuals with cleft lip and palate: a systematic review and meta-analysis. Cleft Palate Craniofac J. 2012;49:194-200.

18. Seo YJ, Park JW, Kim YH, Baek SH. Associations between the risk of tooth agenesis and single-nucleotide polymorphisms of MSX1 and PAX9 genes in nonsyndromic cleft patients. Angle Orthod. 2013;83:1036-42.

19. da Silva AP, Costa B, de Carvalho Carrara CF. Dental anomalies of number in the permanent dentition of patients with bilateral cleft lip: radiographic study. Cleft Palate Craniofac J. 2008;45:473-6.

20. Ranta R. A comparative study of tooth formation in the permanent dentition of Finnish children with cleft lip and palate. An orthopantomographic study. Proc Finn Dent Soc. 1972;68:58-66.

21. DE Stefani A, Bruno G, Balasso P, Mazzoleni S, Baciliero U, Gracco A. Teeth agenesis evaluation in an Italian sample of complete unilateral and bilateral cleft lip and palate patients. Minerva Stomatol. 2018. [Epub ahead of print].

22. Konstantonis D, Alexandropoulos A, Konstantoni N, Nassika M. A cross-sectional analysis of the prevalence of tooth agenesis and structural dental anomalies in association with cleft type in non-syndromic oral cleft patients. Prog Orthod. 2017;18:20.

23. Akcam MO, Evirgen S, Uslu O, Memikoğlu UT. Dental anomalies in individuals with cleft lip and/or palate. Eur J Orthod. 2010;32:20713.

24. Al Jamal GA, Hazza'a AM, Rawashdeh MA. Prevalence of dental anomalies in a population of cleft lip and palate patients. Cleft Palate Craniofac J. 2010;50:413-20.

25. Dentino KM, Peck S, Garib DG. Is missing maxillary lateral incisor in complete cleft lip and palate a product of genetics or local environment? Angle Orthod. 2012;82:959-63.

26. Paradowska-Stolarz A, Dubowik M, Szelag J, Kawala B. Dental anomalies in incisor-canine region in patients with cleft lip and palate - literature review. Dev Period Med. 2014;18:66-9.

27. Vellone V, Cirignaco G, Cavarretta B, Cascone P. Canine eruption after secondary alveolar bone graft in unilateral cleft lip and palate patients. J Craniofac Surg. 2017;28:1206-10.

\section{Acknowledgments}

This study was supported by PROADI - SUS, Brazilian Ministry of Health. The authors thank the Coordination for the Improvement of Higher Education Personnel (CAPES). Mrs. E. Greene provided English editing of the manuscript.

\section{Conflicts of Interest}

The authors have declared that no conflict of interest exist. 